\title{
The young pharmacists (SIF0)
}

\author{
Silvia Adami, ${ }^{1}$ Laura Fabrizio ${ }^{2}$
}

SIFO is a cultural and pharmaceutical association of hospital pharmacists and community pharmacy services for local health centres. SIFO includes nearly all public pharmacists employed within the National Health Service and employees of private hospitals.

SIFO has 2776 members, 686 of which are under the age of 35 and work as hospital pharmacists or in community pharmacy services for local health centres (figure 1). The regions with the most members are Campania (15\%), Emilia Romagna (10\%) and Sicilia (10\%) (figure 2).

Most members are employees in a hospital or territorial pharmacy, only 15\% indefinitely (figure 3). A total of 31\% of young members are postgraduate residents and other members are grant holders (13\%) or self-employed (6\%). Only a small proportion of members (6\%) are community pharmacists.

The Young Pharmacists Group was established in 2008 to delineate a specific role for young pharmacists within the scientific association and to meet the educational and research needs of all young members. ${ }^{1}$ The lack of a permanent job at the end of studies and difficulties during training in hospital pharmacy are important issues for the Young Pharmacists Group. ${ }^{2}$

In Italy, the school of specialisation in hospital pharmacy (SSFO) has undergone extensive changes. It now offers more extensive training-that is, more lessons and longer internships-so that postgraduate residents are unable to work during training This reform has been well accepted by SSFOs and by postgraduate residents; however, it raises important questions about the underlying problem, namely the lack of grants for postgraduate residents.

Another feature of the new SSFOs is that postgraduate residents learn all aspects of hospital and territorial pharmacy. This has not been undervalued because during

${ }^{1}$ Young Pharmacists Group, SIFO, Verona, Italy

${ }^{2}$ SIFO's President, Rome, Italy

Correspondence to Silvia Adami, Coordinator, Young Pharmacists Group, SIFO, Italy; silvia.adami@ymail.com

\section{SIFO's members}

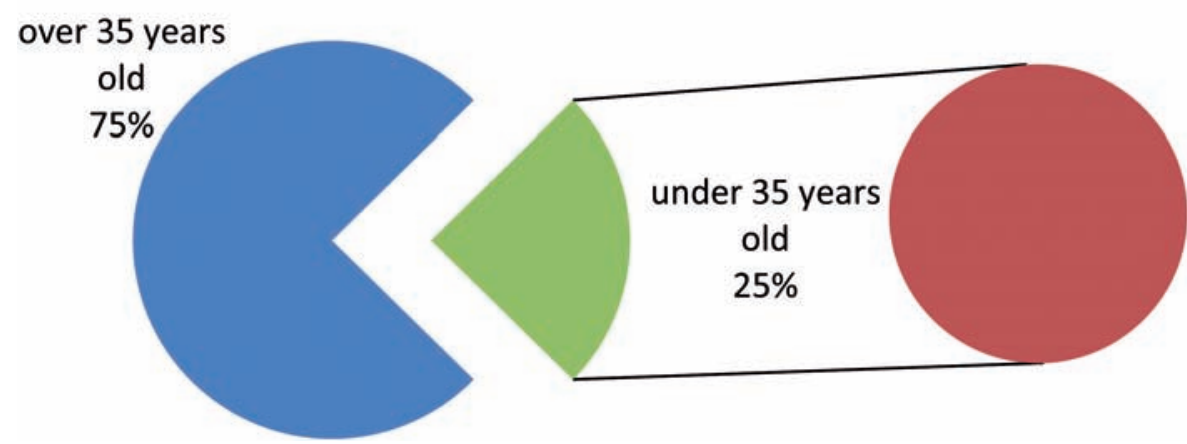

Figure 1 SIFO's members under 35 years old (from SIFO's database, November 2011).

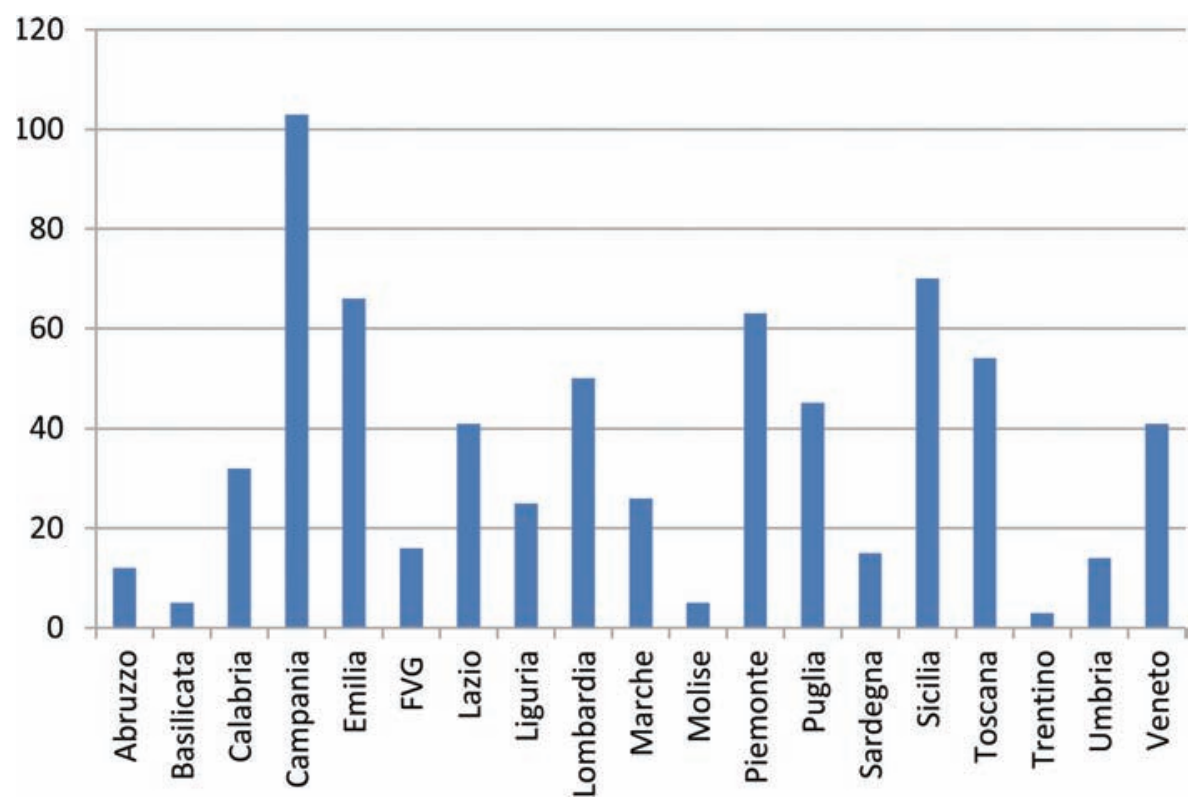

Figure 2 SIFO's members under 35 years old: regional distribution (from SIFO's database, November 2011).

their internship, postgraduate residents should learn as much as they can and should not be 'used' to do unskilled tasks, which unfortunately can happen.

Considering the importance of these issues, the Young Pharmacists Group has organised meetings with representatives from universities to find solutions. One innovative proposal by SIFO emphasises that training should be assessed on the basis of the hours carried out and the 'production' of different activities, moving towards more analytical internship documentation based mainly on quantitative data (eg, days worked in various sectors, number of health technology assessment reports produced). An online register would be created to record all documents produced and projects completed during the internship.

Another critical issue for young pharmacists is the need for continuing education. In the past, postgraduate residents 
were thought to be ready to work at the end of training. Today, this is no longer the case because it has become clear that without continuous updates, pharmacists can lose competence even if they are already working. Therefore, the Young Pharmacists Group has organised training courses that are fundamental for all pharmacists, such as the use of biomedical databases and pharmacovigilance, scientific information and statistical models in clinical trials. ${ }^{3-5}$ Unfortunately, during traditional training activities participants mainly take a listening role, which tends not to change professional practice, whereas initiatives that actively involve participants and provide practical tools do make a difference. Therefore, the Young Pharmacists Group has aimed to involve colleagues in research projects in which all pharmacists can contribute to training in specific research areas. ${ }^{6-11}$ The most important project is about formularies ('IPER-PTO Project'), which is proving valuable for local and national health. ${ }^{6-8}$

In Italy, the Therapeutic Hospital Formulary was most prominent during the 1980s and 1990s, when pharmacological treatments supported by sufficient efficacy data were separated from those without supporting data. Currently the scenario has radically changed, mainly due to the greater efficiency of regulatory agencies (eg, European Medicines Agency (EMA), Italian Drug Agency (AIFA)), which has prevented market access to therapies without so-called evidence. Therefore, the Therapeutic Hospital Formulary is nowadays likely to be considered as simply a positive list, integrated by short 'notes' at best.

The IPER-PTO Project aims to realise a model formulary with a structure that is directly integrated with the concept of guidelines. This project aims to make a hypertext formulary (IPER-PTO) based on guidelines that is a tool of clinical governance and is available online. Therefore, it will only

\section{Under 35 pharmacists: Employement status}

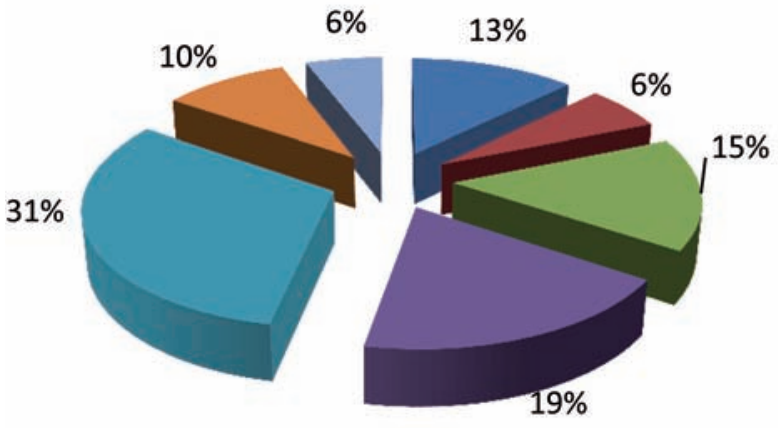

(1)

Figure 3 SIFO's members under 35 years old: employment status (from SIFO's database, November 2011).

be possible to add active agents to the IperPTO if they are accompanied by a guideline indicating their 'place in therapy'. Currently the database contains about 400 active agents and 236 guidelines.

Continuing education is an important component of SIFO's activities and is widely agreed to be an objective that ranks as high as research. So, as well as planning research, the association will be seeking to develop new professional patterns.

\section{Competing interests None.}

Provenance and peer review Commissioned; internally peer reviewed.

Received 23 January 2012

Accepted 27 January 2012

\section{References}

1. S Adami, M Barbieri, S Cammarata, et al. Spazio ai giovani: è nato il Gruppo Giovani della SIFO. Bollettino SIFO 2008:54:278.

2. D Maratea, S Adami, A D'Arpino, et al. Primo incontro interregionale del Gruppo Giovani SIFO Toscana-Umbria. Bollettino SIFO 2011;57:134-5.

3. S Adami, M Barbieri, S Cammarata, et al. Una 'giovane' sifo: il gruppo giovani. 6-8 Ottobre 2010, Diritto alla salute e sostenibilità in una sanità feder- ale. Giomale Italiano di Farmacia Clinica 2010;24:383-4

4. S Simbula, S Adami. Gruppo Giovani: progettualità 2010-2011. Giornale Italiano di Farmacia Clinica 2010;24:158-9.

5. S Adami, M Barbieri, S Cammarata, et al. Le Giornate di formazione del gruppo giovani SIFO: Dalle banche all'informazione scientifica: gli strumenti di documentazione e di divulgazione. Applicazioni in farmacovigilanza, Firenze, 16 Aprile 2010-Napoli, 14 Maggio 2010. Bollettino SIFO 2010;56:227.

6. S Adami, A Messori, S Simbula, et al. Una Nuova Stagione Dei Prontuari Terapeutici Ospedalieri: Esperienza Pilota Del Progetto Pto-Icd-Lg. Giornale Italiano di Farmacia Clinica 2009;23:259.

7. SM Cammarata, S Adami, A Paciello, et al. Progetto IPER-PTO: le linee-guida come base per la stesura dei prontuari. 6-8 Ottobre 2010, Diritto alla salute e sostenibilità in una sanità federale. Giornale Italiano di Farmacia Clinica 2010;24:341.

8. S Cammarata, S Adami, A Paciello, et al. Inizia la seconda fase del progetto iperpto. Giornale Italiano di Farmacia Clinica 2011:25:336-7.

9. S Adami, S Simbula, S Cammarata, et al. Progetto IPERFV: la farmacovigilanza tra informazione e ricerca. 6-8 Ottobre 2010, Diritto alla salute e sostenibilità in una sanità federale. Giornale Italiano di Farmacia Clinica 2010;24:377

10. E Peluso, S Simbula, D Zanon, et al. Progetto sifo iper-fv: aggiornamenti. Giornale Italiano di Farmacia Clinica 2011;25:286.

11. D Passaro, S Adami, S Simbula, et al. Osservatorio Innovazione Sifo (Sezione Farmaci). Giornale Italiano 